\title{
Distribution of TN and TP in Dongchang Lake from Sediment and Non-sediment Water Recharge Based on MIKE21
}

\author{
Zhiran $\mathrm{Xin}^{1}$ and Liqing Ren ${ }^{2 *}$ \\ ${ }^{1}$ Ocean University of China, College of Environmental Science and Engineering, 266000 Qingdao, China \\ ${ }^{2}$ Urumuqi Meteorological Satellite Ground Station, 830011 Urumuqi, China
}

\begin{abstract}
With the continuous increase of urban population, the eutrophication of urban lakes is becoming more and more serious. It is necessary to improve the ecological environment of lakes by water supplement. In this study, TN (total nitrogen) and TP (total phosphorus) of Dongchang Lake before and after water replenishment were sampled and measured, and the hydrodynamic, water quality and sediment MIKE21 models of Dongchang Lake were established. Finally, the variation trend of TN and TP of Dongchang Lake before and after water replenishment of sediment and non-sediment water were simulated, and the following conclusions are drawn: During water replenishment, the TP concentration of each point will rise, and the TP concentration of non-sediment water is higher. After the completion of the water replenishment process, the TP concentration at each point decreases in turn. Under the two water replenishment modes, the difference of TP concentration gradually become narrower, but the TP concentration in non-sediment water is higher. The change trend of TN is similar to that of TP, but after the increase of TN concentration caused by water supply, the concentration of TN remains high in the next few days. This study provides an empirical basis for the development of lake water environment improvement strategies.
\end{abstract}

\section{Introduction}

The development of cities requires the use of various functions of water bodies in the city, among which the value of urban lakes is more reflected in tourism, entertainment, flood storage and drainage, climate regulation and improvement of urban ecological environment. However, with the continuous increase of urban population, the pollution load of urban lakes increases gradually, and eutrophication is becoming more and more serious ${ }^{[1,2]}$.

Dongchang Lake, as a water deficient artificial shallow water lake in the north, has no natural river inflow, and its water supply mainly depends on rainfall and Yellow River. In recent years, the water quality and water quantity of Dongchang Lake are threatened. Because there are a lot of suspended sediment in the Yellow River water, on the one hand, suspended particles are the carrier of pollutants in water, which can help the transport and transformation of pollutants in water environment; on the other hand, water environment can provide the media that influences the chemical and biological changes of various pollutants, which aggravates the dynamic circulation of pollutants The complexity of the ring eventually destroyed the lake water ecological environment ${ }^{[3,4]}$.

Aiming to improve the water quality of Dongchang Lake, this paper used Mike21 to construct twodimensional hydrodynamic, sediment and water quality model, designed different simulation schemes, and explored the influence of sediment water and nonsediment water on pollutants during water replenishment. This research provides empirical basis for the formulation of lake water environment improvement strategy.

\section{Materials and methods}

\subsection{Sample collection and processing}

\subsubsection{Sampling station and sampling time}

Dongchang Lake is located in Liaocheng, Shandong Province. The specific study area is shown in Fig. 1. Dongchang Lake is divided into six lake areas and was surrounded by the ancient city of Liaocheng. Many rivers flow into the lake, which is rich in water resources. The Yellow River, Jindi River, Wei canal and other rivers make the average annual runoff of the study area reach 36.62 billion cubic meters.

\subsubsection{Sample collection and pretreatment}

From April 23 to 26, 2012, the whole process of water replenishment in Dongchang Lake was monitored and sampled. The process of water supplement started from 17:30 on April 23 to 22:00 on April 24. 12 monitoring sites on the lake surface were located by GPS, and surface water and sediment samples were collected. From April 23

\footnotetext{
${ }^{*}$ Corresponding author: 1224199212@qq.com
} 
to 25 , five monitoring points along the vertical section from the inlet to the outlet were selected for synchronous monitoring and sampling. 5 sampling sites are (1) general water inlet, (2) Longwan water supply outlet, (3) wetland island, (4) Nanguan bridge and (5) power plant. The location of sampling points is shown in Figure. 2.

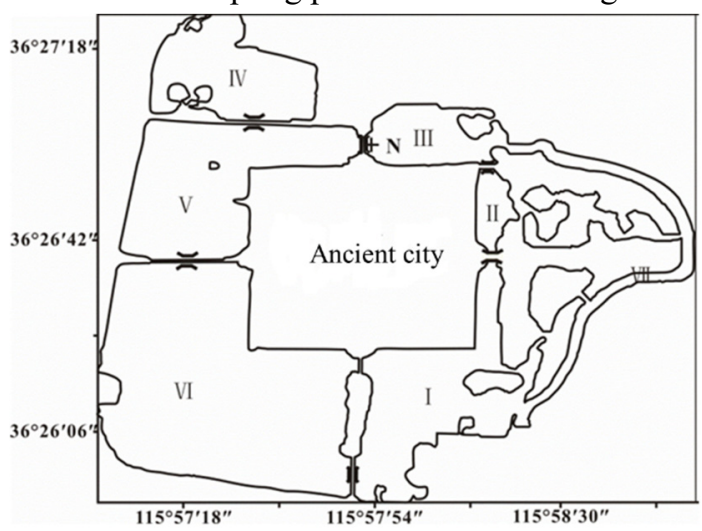

Fig. 1. Map of Dongchang Lake

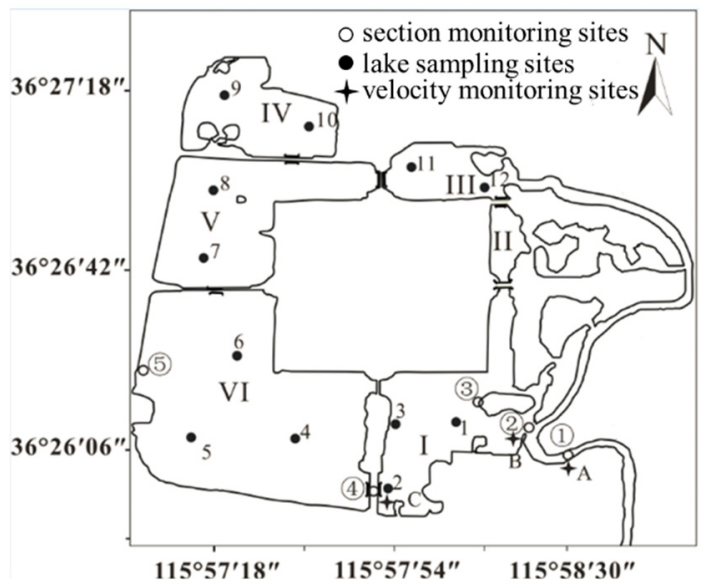

Fig. 2. Map of sampling sites

TN and TP were detected in this study. TN was detected by alkaline potassium persulfate digestion ultraviolet spectrophotometry method, and TP was detected by potassium persulfate molybdenum - antimony anti spectrophotometry method ${ }^{[5,6]}$. The above instruments used for measuring absorbance are ultraviolet spectrophotometer (PERSEE, TU-1810).

\subsection{Construction of MIKE21 model}

\subsubsection{Model generalization in study area}

MIKE21 model was used in this study ${ }^{[7]}$. The model was established based on the data of lake bottom elevation from 2009 to 2011. From 2009 to 2012, Dongchang Lake was investigated and sampled for four times, and relevant measured data were obtained. Hydrometeorological data of evaporation, rainfall, wind speed and wind direction in Dongchang Lake were obtained by local environmental protection agency, meteorological station and other units. Data of flow rate, flow quantity and water quality parameters were obtained by on-site monitoring, sampling and indoor experiment.

During MIKE21 model generalization, firstly established the time series file, including wind direction, wind speed, water supplement, rainfall and concentration of organic nitrogen, inorganic nitrogen, organic phosphorus and inorganic phosphorus. The above data parameters were imported into the time series file editor to make the corresponding time series file. After the hydrodynamic and sediment models were established, organic nitrogen, inorganic nitrogen, organic phosphorus and inorganic phosphorus concentration distribution maps of the lake were interpolated by using the grid generator to provide background values for the model, so as to make the lake simulation more consistent with the real state of Dongchang Lake. The mesh generator was used to preprocess the terrain file. The upper boundary was set at the initial section of the canal entering Dongchang Lake. Taking the simulation of organic nitrogen as an example, the distribution of organic nitrogen in Dongchang Lake is shown in Fig. 3. The flow data of Dongchang Lake during water replenishment period was used. The lower boundary was set at the water inlet of the power plant. The mesh was generated by finite volume method, including 1895 points and 3015 triangular meshes, which could meet the accuracy requirements.

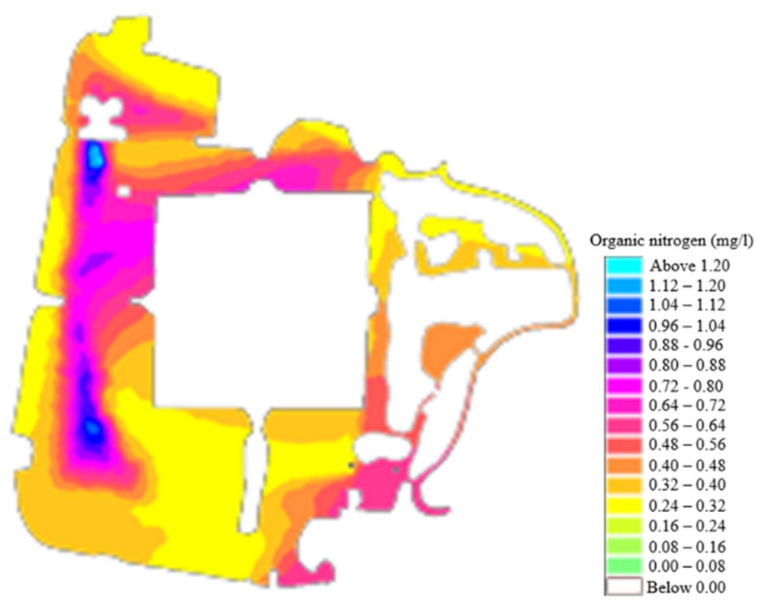

Fig. 3. Concentration distribution maps of organic nitrogen

\subsubsection{Model scheme parameter setting}

Parameters of hydrodynamic and water quality coupling model: influent quantity: $20 \mathrm{~m}^{3} / \mathrm{s}$, TN: $7.01 \mathrm{mg} / 1$, TP: 1.27 $\mathrm{mg} / \mathrm{l}$, influent time: $24 \mathrm{~h}$, influent start time: 8:00 on April 21, 2012. Wind speed, wind direction, rainfall and evaporation adopted the measured values.

Parameters of hydrodynamic, water quality and sediment model: sediment concentration: $1.5 \mathrm{~kg} / \mathrm{m}^{3}$, other parameters were same with hydrodynamic and water quality coupling model.

\subsubsection{Model calibration}

The measured values of flow quantity, flow velocity and concentration of sediment, total nitrogen and total phosphorus from April 23 to April 25 were used for calibration, and the relevant parameters of the model were 
determined within the allowable error range. Taking the flow rate as an example, the calibration effect is shown in Fig. 4.

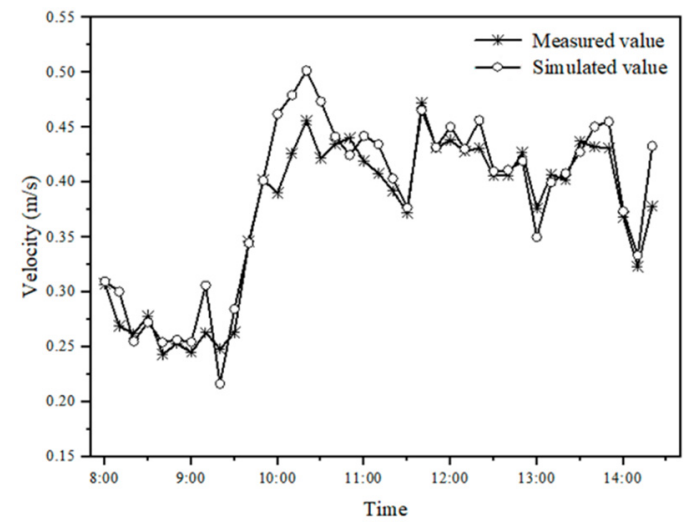

Fig. 4. Comparison of measured and simulated velocity

\section{Results and discussions}

\subsection{Impact of replenishment of sediment water on TN in Dongchang Lake}

During and after water replenishment, TN concentration of sediment water replenishment is always lower than that of non-sediment water replenishment, and the difference between them is large. However, the concentration difference of TN in the vicinity of the water supply outlet was extremely narrow, while it did not appear in other control points. In addition, the TN in the water supply outlet remained at a high level for a long time. As shown in Fig. 5, the TN concentrations of the two schemes are close to each other near the northeast water supply outlet $\left(12^{\#}\right)$, while the other control points $\left(9^{\#}\right.$ and $\left.11^{\#}\right)$ will not appear. In addition, it can be seen from the figure that after the TN concentration of each control point increases, it will maintain a higher concentration in the next few days. This is because suspended sediment can adsorb, degrade and remove nitrogen, but the adsorption capacity is weaker than that of phosphorus. Therefore, when the sediment adsorption reaches saturation, the nitrogen in the water will not be removed, and the TN concentration will reach the maximum value after a period of water supplement. Furthermore, although the suspended sediment carried away part of $\mathrm{TN}$, the self-purification capacity of the lake to $\mathrm{N}$ was limited, so the $\mathrm{TN}$ concentration remained high for a long time, and decreased slowly with the passage of time.

TN concentration is also lower in the control point which is less affected by sediment, while TN concentration is higher in the non-sediment water supply, which is consistent with the distribution of TP concentration.

\subsection{Impact of replenishment of sediment water on TP in Dongchang Lake}

The results show that the suspended sediment has a great influence on the distribution of TP, and the general trend of TP concentration on each control point is lower than that of non-sediment water.

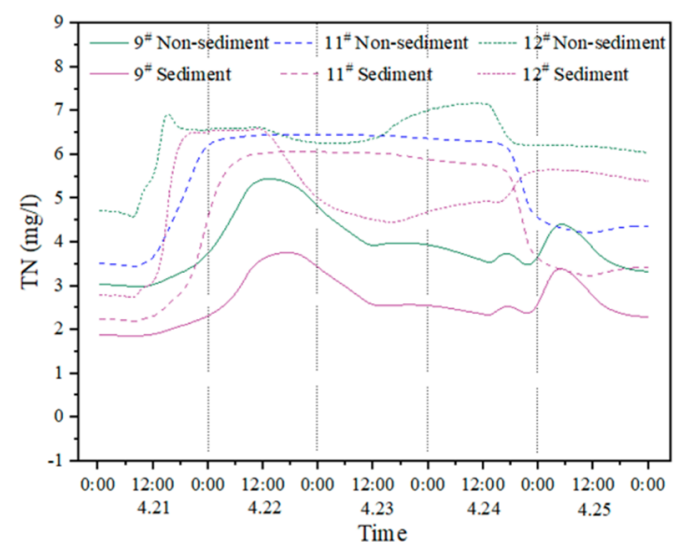

Fig. 5. Variation of TN concentration at 9,11 and 12 points

In the process of water replenishment, the TP concentration at each point will rise (Fig. 6), and finally reach the maximum value. There is a big difference between the two water replenishment methods, and the TP concentration in non-sediment water is higher. For example, the TP concentration of each point in Fig. 6 can exceed $1.2 \mathrm{mg} / \mathrm{l}$ under the condition of non-sediment water supplement, while the maximum concentration of sediment water supplement is only $0.7 \mathrm{mg} / 1$, and the change is gentle. The phosphorus content in the Yellow River water is higher than that in Dongchang Lake, so the $\mathrm{TP}$ concentration at each control point has a rising process after the start of water replenishment; in the process of water replenishment with sediment, the concentration of suspended sediment in the water body is higher, and the adsorption capacity of suspended sediment for phosphorus is very strong, which is consistent with the previous indoor test results, such as Guo pointed out through indoor simulation experiments that the amount of phosphorus adsorption by sediment was large, and the phosphorus adsorption rate reached $53.14 \%$ in the first two hours ${ }^{[8]}$. Wang also proved through indoor simulation experiments that suspended sediment in water has a significant impact on the concentration of various forms of phosphorus pollutants in water, and has a significant adsorption effect on phosphorus [9]. Suspended sediment particles move violently with the replenishment flow, and a large number of phosphorus containing substances such as organic phosphorus and inorganic phosphorus are attached on the surface, which settle to the bottom when the flow slows down. Therefore, most of the phosphorus load carried by the Yellow River water is deposited in the area near the replenishment mouth, which is also verified by experiments: the phosphorus content in the sediment near the replenishment mouth is relatively high, so the TP content in the replenishment process of sediment water is higher than that in non-sediment water.

After the completion of the water replenishment process, the TP concentration at each point decreases in turn. Under the two water replenishment modes, the difference of TP concentration gradually decreases, but the TP concentration of non-sediment water replenishment is higher (Fig. 6). This is because when the lake replenishes 
the sediment laden water, part of the substance containing $\mathrm{P}$ in the water body is removed by the adsorption and sedimentation of the sediment, resulting in the TP concentration entering the lake is significantly lower than that of the non-sediment laden water. Under the same time and under the same conditions, the TP concentration of the lake is kept at a low level when the sediment laden water is replenished.

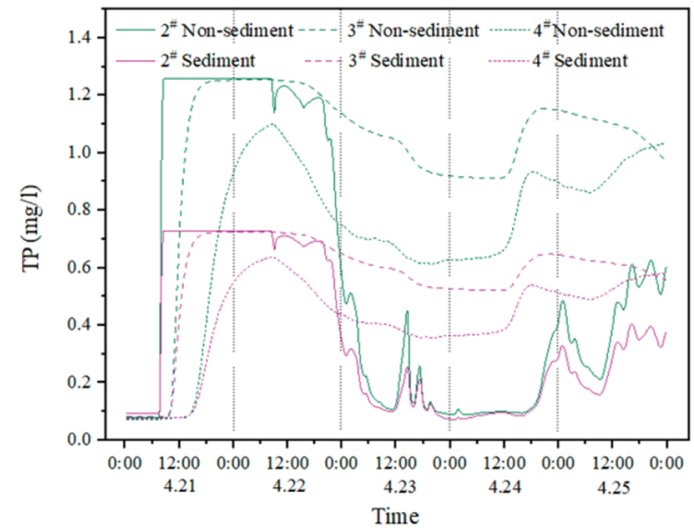

Fig. 6. Variation of TP concentration at 2, 3 and 4 points

When the sediment water is replenished, the control point is less affected by sediment, and TP concentration is at a lower level, while the supply of non-sediment water is still higher than the former. As shown in Fig. 7, TP concentration at each point is lower when sediment water is replenished. This is because TP is gradually removed during the process of water replenishment through the attachment and settlement of suspended sediment particles along the way and the self-purification force of the lake. When the water reaches these control points, TP concentration is already at a low level. Instead of sediment water, the self-purification force of the lake is removed, so the effect cannot reach the former.

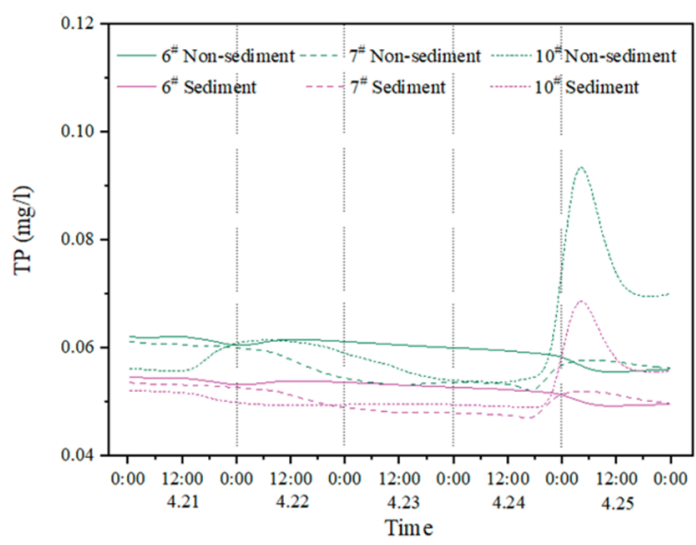

Fig. 7. Variation of TP concentration at 6,7 and 10 points

\section{Conclusions}

In this study, TP and TN of Dongchang Lake before and after water replenishment were sampled and measured. After using MIKE21 model to establish the hydrodynamic, water quality and sediment model of Dongchang Lake, the measurement parameters were brought in. Finally, the variation trend of TN and TP of Dongchang Lake before and after water replenishment of sediment and nonsediment water was simulated.

Due to the adsorption and sedimentation of sediment, the TP concentration of each point will rise in the process of water supplement, and the TP concentration of non0sediment water is higher. After the completion of the water replenishment process, the TP concentration at each point decreased in turn. Under the two water replenishment modes, the difference of TP concentration gradually narrowed, but the TP concentration in nonsediment water was higher.

The change trend of TN was similar to that of TP, but after the increase of $\mathrm{TN}$ concentration caused by water supply, the concentration of TN remained high in the next few days. This is because the adsorption and sedimentation of $\mathrm{N}$ by sediment is weaker than that of $\mathrm{P}$, and the self-purification ability of Dongchang Lake to $\mathrm{N}$ is limited ${ }^{[10]}$.

\section{References}

1. S.S. Lin, S.L. Shen, A. Zhou, H.M. Lyu, Sci. Total Environ. 751, 141618 (2004)

2. Y. Wang, X. Kong, Z. Peng, H. Zhang, G. Liu, W. Hu, X. Zhou, Environ. Sci. Pollut. Res. 27, 41488 (2020)

3. Z. Ni, S. Wang, Environ. Sci. Pollut. Res. 22, 18561 (2015)

4. A. Reza, J. Eum, S. Jung, Y. Choi, J.S. Owen, B. Kim, Environ. Monit. Assess. 188, 692 (2016)

5. Y. Kuo, W. Liu, E. Zhao, R. Li, R. Muñoz-Carpenab, J. Hydrol. 569, 218 (2019)

6. S. Lu, X. Jin, G. Yu, Ecol. Environ. 15, 391 (2006)

7. C.A. Gaonkar, S.V. Samiksha, G. George, V.M. Aboobacker, P. Vethamony, A.C. Anil, 94, 218 (2012)

8. C. Guo, China Water \& Wastewater 22, 10 (2001)

9. X. Wang, Z. Li, P. Lv, Resour. Environ. Yangtze Basin 16, 31 (2007)

10. L. Zhang, W. Cao, Y. Ma, C. Han, Y. Qin, Y. Zhao, Z. Liu, C. Yang, Environ. Sci. 37, 1677 (2016) 